\title{
Influence of Hydrogen-Bonding Additives on Electrospinning of Cyclodextrin Nanofibers
}

\author{
Fuat Topuz*(i) and Tamer Uyar*() \\ Institute of Materials Science \& Nanotechnology, UNAM-National Nanotechnology Research Center, Bilkent University, 06800 \\ Ankara, Turkey
}

\section{Supporting Information}

ABSTRACT: The electrospinning of highly concentrated solutions of cyclodextrin (CD) leads to bead-free nanofibers without the need of a polymeric carrier. The occurrence of numerous hydrogen bonds among CD molecules is the main driving force for their electrospinning, and hence, additives with hydrogen-bonding potential can disturb the aggregation of $\mathrm{CD}$ molecules and affect their electrospinning. In this study, we systematically investigated the influence of five different hydrogen-bonding additives, i.e., methylamine (MA), ethylenediamine (ED), urea, 2,2,2-trifluoroethanol (TFE), and 1,1,1,3,3,3hexafluoroisopropanol (HFIP), on the solution behavior of hydroxypropyl $\beta$ CD (HP- $\beta$-CD) by rheology, conductivity, and NMR analyses, and the morphology of the electrospun HP- $\beta$-CD nanofibers by scanning electron microscopy. The ${ }^{1} \mathrm{H}$ NMR chemical shifts of the HP- $\beta$-CD protons in $\mathrm{D}_{2} \mathrm{O}$ were observed with the incorporation of hydrogen-bonding molecules due to the

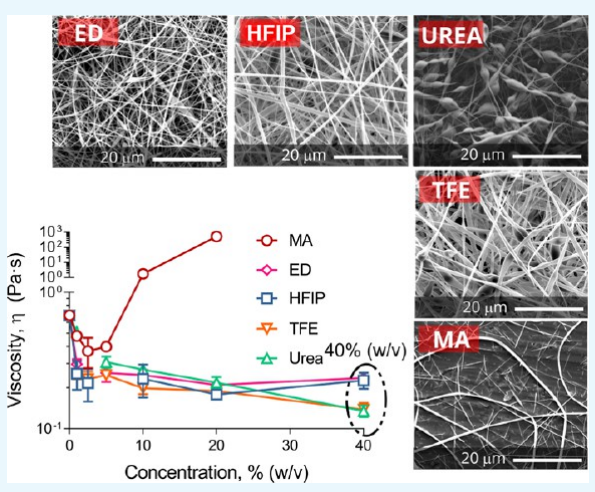
occurrence of intermolecular associations between HP- $\beta$-CD and additives. Dynamic light scattering measurements revealed a clear decrease in the aggregate size with the introduction of additives. Unlike other additives, which showed a general decreasing trend in viscosity with increasing additive content, the addition of MA led to a significant increase in the viscosity with increasing concentration and gave rise to HP- $\beta$-CD nanofibers at lower concentrations. The addition of low concentrations of ED, urea, TFE, and HFIP led to thinner nanofibers due to the lower viscosity of the respective solutions. Increasing additive content deteriorated the electrospinnability of HP- $\beta$-CD solutions, resulting in beaded fibers. A systematic relationship was found between the solution viscosity and morphology of the respective electrospun fibers. Overall, this study, for the first time, reports the influence of hydrogen bonding on the polymer-free electrospinning of $\mathrm{CD}$ molecules and shows a correlation between solution properties and morphology of their electrospun nanofibers.

\section{INTRODUCTION}

Cyclodextrin $(\mathrm{CD})$ is a cyclic oligomer with various numbers of glucopyranose units and has a toroidal structure with a relatively hydrophobic cavity interior and a hydrophilic exterior. ${ }^{1}$ The inner cavity of $\mathrm{CD}$ acts as a molecular host for small hydrophobic molecules or portions of large molecules and forms inclusion complexation with appropriately sized molecules. ${ }^{2}$ CDs have therefore been widely used in various forms for a wide spectrum of applications, including textile ${ }^{3-5}$ and food industry, ${ }^{6,7}$ biomedical field, ${ }^{8-11}$ and water treatment. $^{12-15}$

The electrospinning of CD solutions without the need of a polymeric carrier was previously reported in various solvent systems using different $\mathrm{CD}$ types, e.g., native $\mathrm{CDs}\left(\alpha\right.$-CD, ${ }^{16,17}$ $\beta$-CD, ${ }^{16-18}$ and $\left.\gamma-\mathrm{CD}^{17,19}\right)$ and chemically modified CDs (hydroxypropyl (HP) $\mathrm{CDs}^{20-22}$ and methylated $\mathrm{CDs}^{23}$ ). Further, CD-inclusion complexes were successfully electrospun into nanofibers without using any polymeric carrier. ${ }^{24-27}$ The presence of numerous hydrogen bonds between $\mathrm{CD}$ molecules is the main driving force for the formation of polymer-free CD nanofibers, which requires highly concentrated solutions to be able to produce a single continuous jet from their solutions.
Due to their low water solubility, the aqueous solutions of native $\mathrm{CD}$ molecules cannot be used for electrospinning under mild conditions, except their highly alkaline solutions to break hydrogen bonds among CD molecules ${ }^{16}$ or use their solutions in polar aprotic solvents, such as a combination of dimethylformamide (DMF) and ionic liquid. ${ }^{18}$ Therefore, modified CD derivatives were mostly exploited in the polymerfree electrospinning of $\mathrm{CD}$ molecules. Particularly, hydroxypropyl (HP), ${ }^{20}$ randomly methylated, ${ }^{23}$ and sulfobutyl ether $(\mathrm{SB})^{27}$-modified CD molecules have high solubility, exceeding $10^{3} \mathrm{~g} / \mathrm{L}$ in water and dimethylformamide (DMF) and could form highly concentrated solutions to be electrospun into fibers in the absence of a polymeric carrier. Likewise, the highly concentrated solutions of tannic acid could recently be electrospun into nanofibers without the requirement of a polymeric carrier in water/ethanol mixtures owing to the presence of numerous hydrogen bonds. ${ }^{28}$ The electrospinning of such small molecules is governed by the presence of

Received: October 5, 2018

Accepted: December 14, 2018

Published: December 26, 2018 
Scheme 1. Chemical Structures of Additives Used in this Study, and Their Potential Hydrogen-Bonding Atoms with Respect to the Hydroxyl Groups of the HP- $\beta$-CD Are Shown in Color

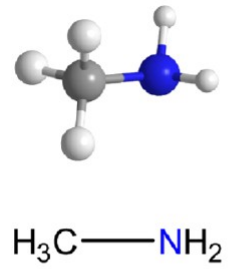

Methylamine (MA)

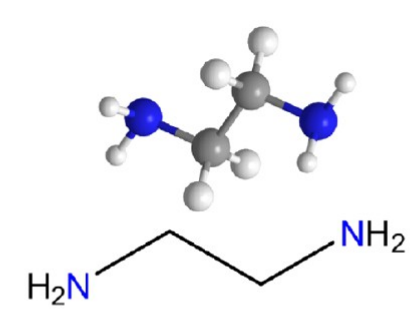

Ethylenediamine (ED)

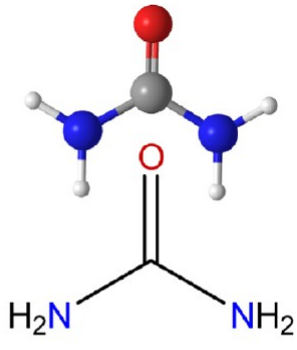

Urea (U)

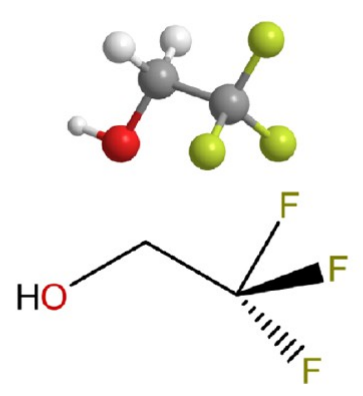

2,2,2-Trifluoroethanol (TFE)

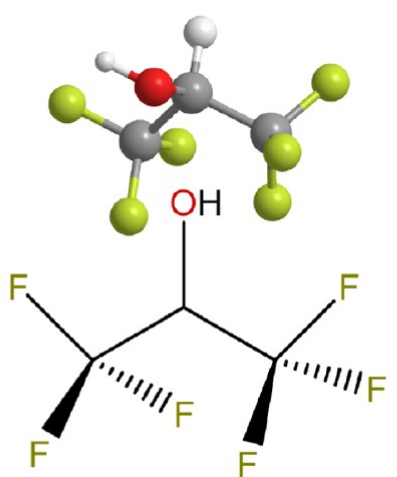

1,1,1,3,3,3-Hexafluoroisopropanol (HFIP) numerous hydrogen bonds and is therefore highly sensitive to additives with hydrogen-bonding potential, such as urea, which can affect their electrospinnability. ${ }^{20}$ The hydrogen-bonded aggregates of $\mathrm{CD}$ molecules can also be disturbed by the ionization of pendant hydroxyl groups, which results in increased solubility. ${ }^{29}$ Although the electrospinning of $\mathrm{CD}$ solutions without using a polymeric carrier has been well studied using different $C D$ types ${ }^{16-23}$ and their inclusion complexes $^{24-27,30,31}$ with a wide range of molecules, the effect of hydrogen bonding on the electrospinnability of $\mathrm{CD}$ molecules has remained an unresolved issue.

Hydrogen bond occurs between two polar groups when a hydrogen atom is bound to a highly electronegative atom having a pair of electrons, such as oxygen $(\mathrm{O})$, nitrogen $(\mathrm{N})$, and fluorine $(\mathrm{F}) .^{32}$ The strength of this bond varies depending on the electronegativity of the atom and increases with higher electronegativity of hydrogen bond acceptor. CD has many hydroxyl groups whose oxygen $(\mathrm{O})$ makes hydrogen bonds with the protons of other hydroxyl groups, water molecules, or amine-functional molecules. ${ }^{21,24,33}$ Recent studies showed that organofluorine compounds can also form hydrogen bonds with water molecules: for instance, $\mathrm{F}$ atom in $\mathrm{CH}_{3} \mathrm{~F}$ acts as a hydrogen bond acceptor in its complex with water, and this bond is about $80 \%$ strong as a hydrogen bond in water dimer. ${ }^{34}$ Another study showed that the fluorine of $\mathrm{RCH}_{2} \mathrm{~F}$ is a superior hydrogen bond acceptor compared to the $\mathrm{RCHF}_{2}$ and $\mathrm{RCF}_{3}$ molecules. $^{35}$

In this study, the influence of hydrogen bonding additives on the electrospinning solution of CD molecules was studied. Five different molecules (i.e., methylamine (MA), ethylenediamine (ED), urea, 2,2,2-trifluoroethanol (TFE), and 1,1,1,3,3,3- hexafluoroisopropanol (HFIP)) having potential hydrogenbonding groups were used as additives (Scheme 1). Viscosity tests were conducted to elucidate intermolecular associations in electrospinning solutions at various concentrations of additives. The occurrence of intermolecular interactions between $\mathrm{CD}$ and additive molecules was also explored by ${ }^{1} \mathrm{H}$ NMR and dynamic light scattering (DLS) analyses. The electrospinning of $\mathrm{CD}$ aggregates in the presence of increasing additive concentration was performed, and the resultant electrospun $\mathrm{CD}$ nanofibers were investigated in terms of morphology by scanning electron microscopy (SEM).

\section{RESULTS AND DISCUSSION}

Due to numerous hydrogen bonds, CD can self-associate to form aggregates in aqueous solutions. In most cases, they form small aggregates so that the solution remains clear and transparent. When the concentration exceeds the critical aggregation concentration (cac), molecular associations dominate the solution behavior and lead to the formation of large aggregates. In this regard, Garnero et al. reported the calculated cac of 2 -hydroxypropyl- $\beta$-cyclodextrin (HP- $\beta$-CD) from both ${ }^{1} \mathrm{H}$ NMR and conductivity analyses to be 77.7 and $69.3 \mathrm{mg} / \mathrm{mL}(\sim 49.5 \mathrm{mM})$, respectively. ${ }^{36}$ On the other hand, Do et al. reported the cac values for various CDs (HP- $\beta$-CD, 2hydroxypropyl- $\gamma$-cyclodextrin (HP- $\gamma$-CD), and sulfobutyl ether- $\beta$-cyclodextrin (SBE- $\beta$-CD) ) from different companies to be $\sim 20 \mathrm{mg} / \mathrm{mL}^{37}$ Apart from these techniques, the aggregation can be supported by evidence from the concentration dependence of viscosity measurement. ${ }^{29}$ However, the electrospinning of $\mathrm{HP}-\beta$-CD molecules takes place in 

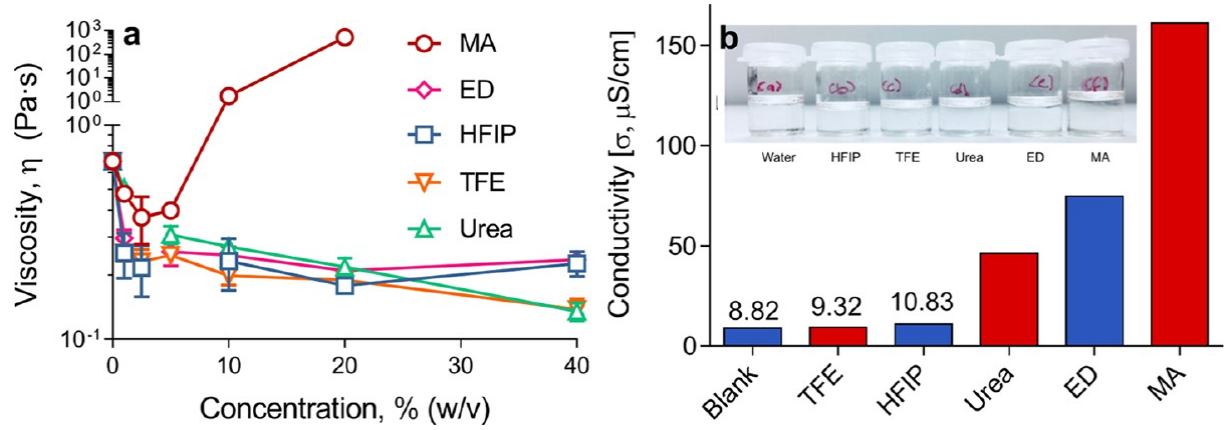

Figure 1. (a) Viscosity ( $\eta$ at the shear rate of $\left.0.1 \mathrm{~s}^{-1}\right)$ of aqueous HP- $\beta$-CD solutions $(c=160 \%(\mathrm{w} / \mathrm{v}))$ containing various concentrations of additives, i.e., HFIP, ED, MA, TFE, and urea. (b) Conductivity of HP- $\beta$-CD solutions containing $20 \%(\mathrm{w} / \mathrm{v}$ ) of additives and an additive-free HP$\beta$-CD solution (noted as blank). The inset shows the optical photo of the HP- $\beta$-CD solutions containing $20 \%$ (w/v) additives.

the highly concentrated regime, in which the concentration of HP- $\beta$-CD exceeds $1600 \mathrm{mg} / \mathrm{mL}$ ( 23-fold of the cac).

All additives, i.e., MA, ED, urea, TFE, and HFIP, are watermiscible molecules and could form homogeneous mixtures. Due to differences in the chemical composition, each of these additives has different hydrogen-bonding potential. Aqueous $\mathrm{HP}-\beta$-CD solutions containing various concentrations of additives formed clear and transparent solutions (Figure $1 \mathrm{~b}$, inset). The flow behavior of these solutions was explored in the shear rate $(\gamma)$ range of $0.01-2000 \mathrm{~s}^{-1}$. All solutions displayed shear thinning behavior with increasing shear rate (Figure S1). The viscosity $(\eta)$ of the solutions decreased with higher concentrations of additives (Figure 1a). This decrease in the viscosity can be ascribed to the partial breakage of hydrogen bonds among HP- $\beta$-CD molecules with the incorporation of additive molecules. Owing to the presence of two electronegative nitrogen $(\mathrm{N})$ atoms linked to the hydrogen bond acceptor carbonyl group, urea is considered as the strongest hydrogen-disrupting molecule among the additives and hence should lead to the lowest viscosity. Therefore, the most obvious decrease was observed for the sample containing urea, followed by TFE. The $\eta$ of the HP- $\beta$-CD solution significantly decreased from $0.677( \pm 0.034)$ to $0.135( \pm 0.013) \mathrm{Pa}$ s with the addition of $40 \%(\mathrm{w} / \mathrm{v})$ urea. Likewise, the $\eta$ decreased to $0.138( \pm 0.016) \mathrm{Pa} \mathrm{s}$ with the incorporation of $40 \%(\mathrm{w} / \mathrm{v})$ TFE. A similar decreasing trend was also observed for the samples containing $40 \%(\mathrm{w} / \mathrm{v})$ of HFIP and ED: $\eta$ decreased to $0.226( \pm 0.030)$ and $0.235( \pm 0.016)$ Pa s with the addition of $40 \%(\mathrm{w} / \mathrm{v})$ HFIP and ED, respectively. Unlike other additives, the addition of MA significantly increased the viscosity: $\eta$ increased from $0.370( \pm 0.092)$ to $516( \pm 68) \mathrm{Pa} \mathrm{s}$ with an increasing MA concentration from 2.5 to $20 \%(\mathrm{w} / \mathrm{v})$ (Figure 1a). The aggregation behavior of CD molecules in the presence of different additives was explored by DLS analysis (Figure S2), where the size of CD aggregates drastically decreased with the incorporation of additives: the size of $C D$ aggregates reduced from $163( \pm 14)$ to $80( \pm 9), 56( \pm 4), 25$ $( \pm 7.8), 24( \pm 4)$, and $16( \pm 5) \mathrm{nm}$ in the presence of $2.5 \%(\mathrm{w} /$ v) TFE, HFIP, ED, urea, and MA, respectively. Thereafter, an increase in the aggregate size was observed with a concentration rise of additives since the actual concentration was higher than the critical aggregation concentration.

Since electrospinning is a process that relies on electrical forces to draw charged jets of highly viscous solutions of polymers and nonpolymeric systems, solution conductivity has a significant impact on the electrospinning process. The conductivity values of HP- $\beta$-CD solutions containing $20 \%$ (w/ v) additives are shown in Figure $1 \mathrm{~b}$, where the conductivity of $160 \%(\mathrm{w} / \mathrm{v}) \mathrm{HP}-\beta$-CD solution was measured as $9 \mu \mathrm{S} / \mathrm{cm}$ because of the poor conductivity of HP- $\beta$-CD molecules in water. However, with the incorporation of additives, the conductivity increased with an order of TFE, HFIP, urea, ED, and MA. Unlike other additives, the addition of $20 \%(\mathrm{w} / \mathrm{v})$ MA drastically increased conductivity to $161 \mu \mathrm{S} / \mathrm{cm}$ (Figure $1 b)$, whereas the conductivity of an $\mathrm{HP}-\beta$-CD solution containing $20 \%(\mathrm{w} / \mathrm{v})$ urea was measured as $46 \mu \mathrm{S} / \mathrm{cm}$.

The occurrence of intermolecular interactions between HP$\beta$-CD and additive molecules was confirmed by ${ }^{1} \mathrm{H}$ NMR analysis, where the proton peaks of $\mathrm{CD}$ molecules revealed negative or positive chemical shifts. The chemical structure of the HP- $\beta$-CD molecule and the assignments of CD protons are shown in Figure $2 \mathrm{a}$, while Figure $2 \mathrm{~b}$ shows the ${ }^{1} \mathrm{H}$ NMR spectra of HP- $\beta$-CD solutions $(c=25 \mathrm{mg} / \mathrm{mL})$ in $\mathrm{D}_{2} \mathrm{O}$ in the absence and presence of $\mathrm{MA}$ of various molar ratios (i.e., $\mathrm{n}_{[\text {additive }] /[\mathrm{CD}]}=0.5,1,2$, and 4$)$. The methyl protons of the hydroxypropyl group show a doublet peak at $1.1 \mathrm{ppm}$, while proton $\mathrm{H} 1$ resonates between 5.03 and $5.2 \mathrm{ppm}$ appearing as two sets of doublets owing to the $\mathrm{H} 1$ protons of hydroxypropyl substituents in different positions. The signal at $5.11 \mathrm{ppm}$ can be attributed to glucopyranose with no substitution, while the peak at $5.2 \mathrm{ppm}$ can be ascribed to the $\mathrm{H} 1$ protons of glucopyranose with HP substituents. A similar spectrum for HP- $\beta$-CD molecules was observed by Chay et al., and the authors attributed this second peak to the hydroxypropylsubstituted glucopyranose. ${ }^{38}$ The other peaks of the HP- $\beta$-CD appeared at $3.578 \mathrm{ppm}$ for $\mathrm{H} 2,3.882 \mathrm{ppm}$ for $\mathrm{H} 3,3.458 \mathrm{ppm}$ for $\mathrm{H} 4,3.781 \mathrm{ppm}$ for $\mathrm{H} 5,3.816 \mathrm{ppm}$ for H6, $3.669 \mathrm{ppm}$ for $\mathrm{H} 7$, and $3.972 \mathrm{ppm}$ for $\mathrm{H} 8 .{ }^{1} \mathrm{H}$ NMR analysis allows the determination of complexation behavior in terms of estimation of the sites of interactions between HP- $\beta$-CD and additives. It is known that $\mathrm{H} 3$ and $\mathrm{H} 5$ protons are located in the $\mathrm{CD}$ cavity, while $\mathrm{H} 1, \mathrm{H} 2$, and $\mathrm{H} 4$ protons are located on the outside of the CD cavity. ${ }^{39}$ The shift in the positions of these protons shows whether the interactions take place as inclusion complexation or hydrogen bonding with the exterior $\mathrm{OH}$ groups of CD molecules. From the spectra shown in Figure 2, the chemical shifts of glucopyranose protons were determined. With increasing MA concentration, the peak intensities drastically dropped, and the chemical shifts of the $\mathrm{H} 1, \mathrm{H} 2$, and $\mathrm{H} 4$ protons were observed, suggesting the existence of interactions between the protons of $\mathrm{HP}-\beta-\mathrm{CD}$ and MA. A similar shift was reported for the complexation of flurbiprofen and $\beta$-CD molecules, and the proton peaks shifted to lower ppm values upon the addition of flurbiprofen. ${ }^{40}$ The change in 
(a)

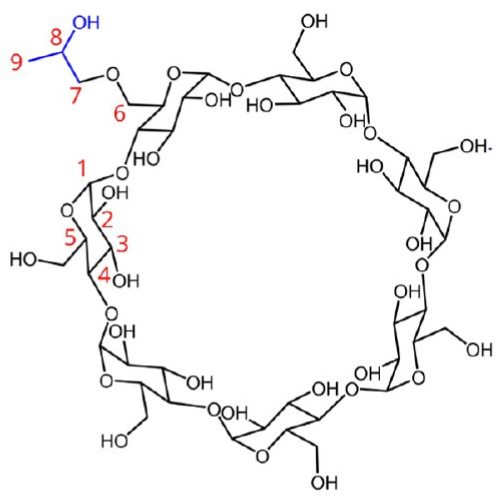

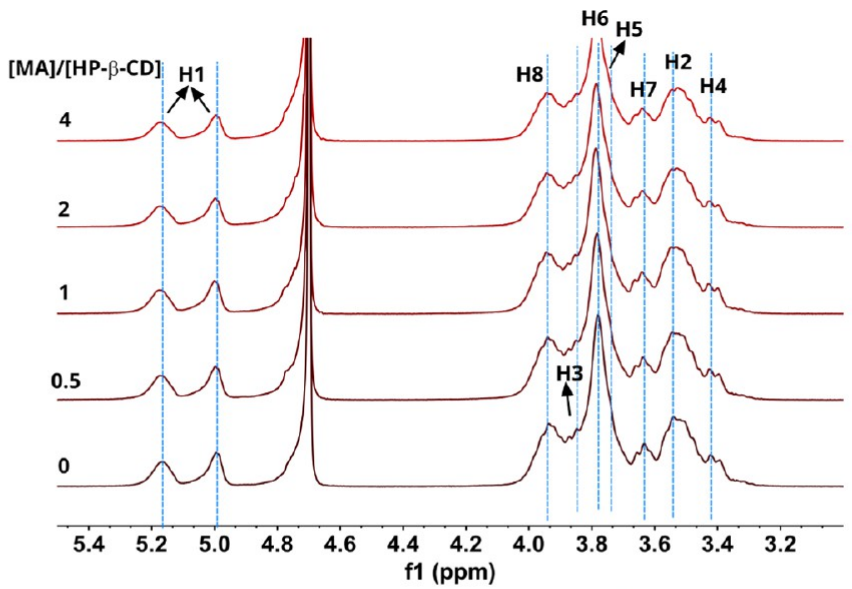
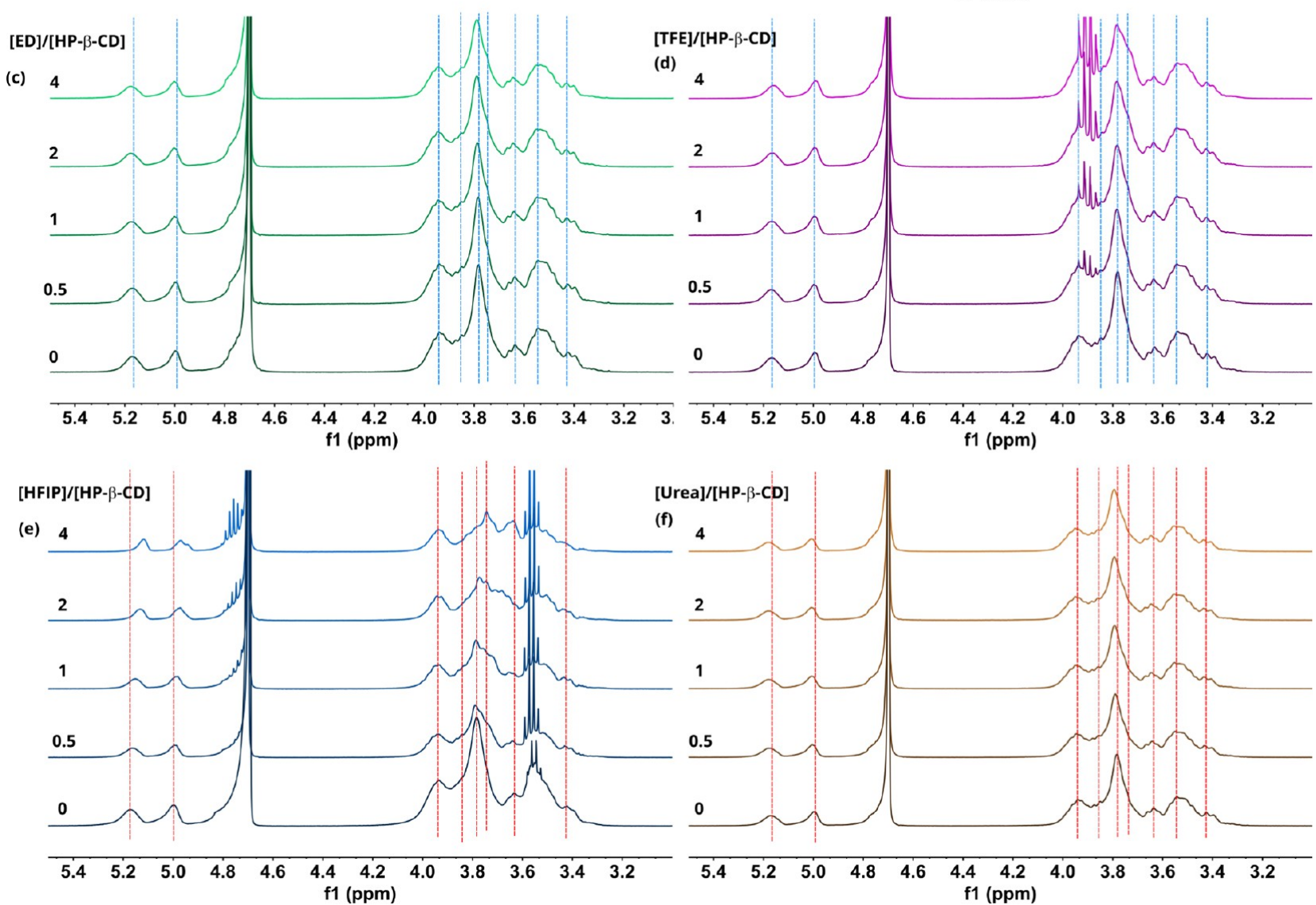

Figure 2. ${ }^{1} \mathrm{H}$ NMR spectra of the HP- $\beta$-CD solutions in $\mathrm{D}_{2} \mathrm{O}$ containing various concentrations of additives. (a) Chemical structure of HP- $\beta$-CD molecule, and ${ }^{1} \mathrm{H}$ NMR spectra of the HP- $\beta$-CD in $\mathrm{D}_{2} \mathrm{O}$ containing various concentrations of additives indicated: (b) MA, (c) ED, (d) TFE, (e) HFIP, and (f) urea.

chemical shifts $(\Delta \delta)$ in the absence and presence of an additive molecule was followed over the same protons, i.e., $\Delta \delta=$ $\delta_{\mathrm{HP}-\beta \text {-CD/additive }}-\delta_{\mathrm{HP}-\beta \text {-CD }}$. Upon addition of higher amount of MA, clear shifts were observed for $\mathrm{H} 1, \mathrm{H} 2$, and $\mathrm{H} 4$, suggesting the presence of interactions between MA and the exterior protons of the HP- $\beta$-CD. On the other hand, proton chemical shifts were more distinctive for other additives (Figure $2 c-f$ ). The most obvious changes were observed for HFIP, followed by ED, urea, MA, and TFE. The addition of increasing concentration of ED led to the chemical shifts of HP- $\beta$-CD protons (Figure $2 \mathrm{c}$ ). HP- $\beta$-CD protons shifted to higher $\mathrm{ppm}$ with the addition of higher concentration of $\mathrm{ED}$, whereas the incorporation of higher amount of HFIP shifted the HP- $\beta$-CD protons to lower ppm (Figure 2e). A similar trend was observed for TFE, demonstrating that both TFE and HFIP similarly interacted with HP- $\beta$-CD molecules (Figure $2 \mathrm{~d}$ ). However, the addition of urea led to the downfield of $\mathrm{H} 1$ protons of HP- $\beta$-CD molecules (Figure $2 \mathrm{f}$ ). Overall, ${ }^{1} \mathrm{H}$ NMR studies showed the presence of interactions between additives and $\mathrm{HP}-\beta-\mathrm{CD}$ molecules, and these interactions led to the chemical shifts of HP- $\beta$-CD protons with an increasing concentration of additives. The incorporation of MA and ED showed obvious chemical shifts for the exterior protons of $\mathrm{CD}$ molecules (Figure 3a,b). On the other hand, other additives likely formed inclusion complexation with $\mathrm{CD}$ molecules due 

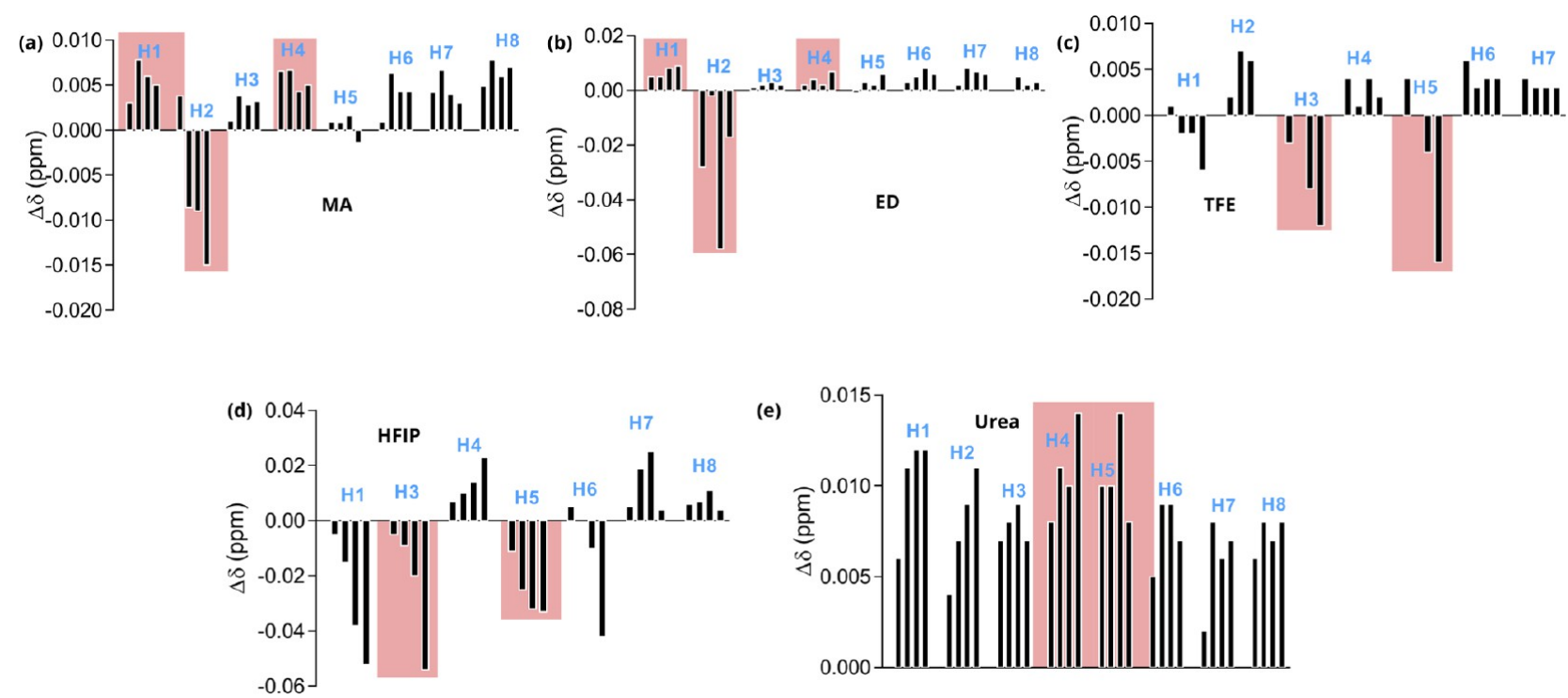

Figure 3. Chemical shifts of HP- $\beta$-CD in $\mathrm{D}_{2} \mathrm{O}$ containing increasing concentrations of additives indicated: (a) MA, (b) ED, (c) TFE, (d) HFIP, and (e) urea.

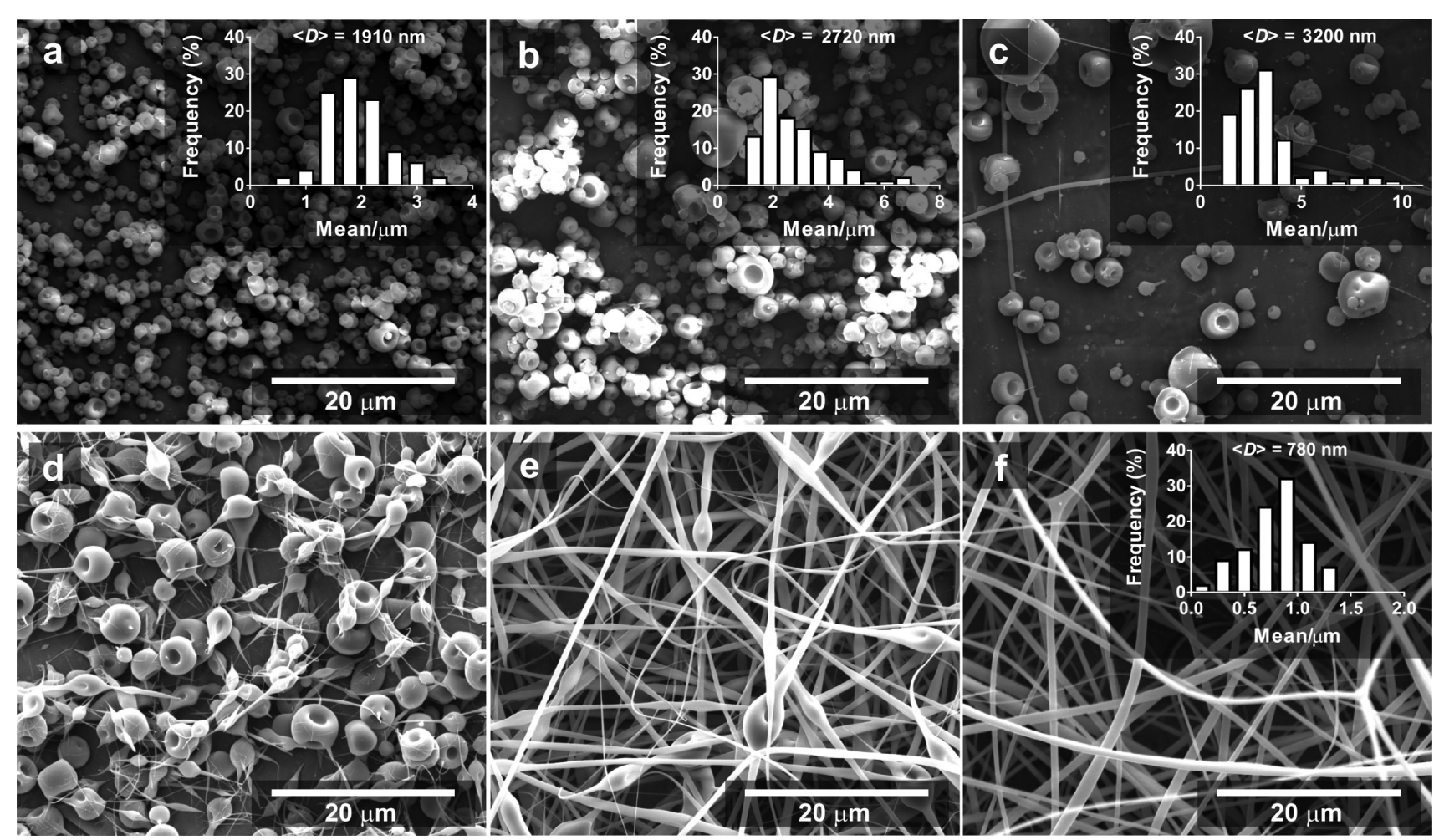

Figure 4. Scanning electron micrographs of the HP- $\beta$-CD beads and nanofibers produced at various concentrations: (a) $60 \mathrm{wt} \%$, (b) $80 \mathrm{wt} \%$, (c) $100 \mathrm{wt} \%$, (d) $120 \mathrm{wt} \%$, (e) $140 \mathrm{wt} \%$, and (f) $160 \mathrm{wt} \%$. The insets show the size distribution plots of the electrosprayed HP- $\beta$-CD beads (a-c). Inset (f) shows the size distribution plot of the nanofibers.

to chemical shifts in the positions of $\mathrm{H} 3$ and $\mathrm{H} 5$ protons (Figure 3c,e).

The electrospinning of the HP- $\beta$-CD solutions at various concentrations was performed, and the formation of electrosprayed beads and beaded fibers was observed at the HP- $\beta$-CD concentration of $\leq 120$ wt $\%$ (Figure 4 ). The diameter of electrosprayed beads increased with higher HP- $\beta$-CD content, at which only HP- $\beta$-CD microsized beads were formed at $60 \%$ $(\mathrm{w} / \mathrm{v})$ with a mean bead diameter of $1.91 \mu \mathrm{m}$. On the other hand, the electrosprayed beads obtained at the $100 \%(\mathrm{w} / \mathrm{v})$
HP- $\beta$-CD were $3.20 \mu \mathrm{m}$ in diameter, suggesting enhanced intramolecular interactions with a concentration rise of the HP- $\beta$-CD so that larger beads were formed. The solution containing $120 \%(\mathrm{w} / \mathrm{v}) \mathrm{HP}-\beta$-CD led to extended beads, while beaded fibers were observed at the HP- $\beta$-CD concentration of $140 \%(\mathrm{w} / \mathrm{v})$. The increase of the HP- $\beta$-CD concentration to $160 \%(\mathrm{w} / \mathrm{v})$ led to bead-free HP- $\beta$-CD nanofibers with a mean diameter of $780 \mathrm{~nm}$. These results are consistent with the previous report on the electrospun nanofibers obtained at the identical concentration of HP- $\beta$-CD molecules in water. ${ }^{20}$ The 


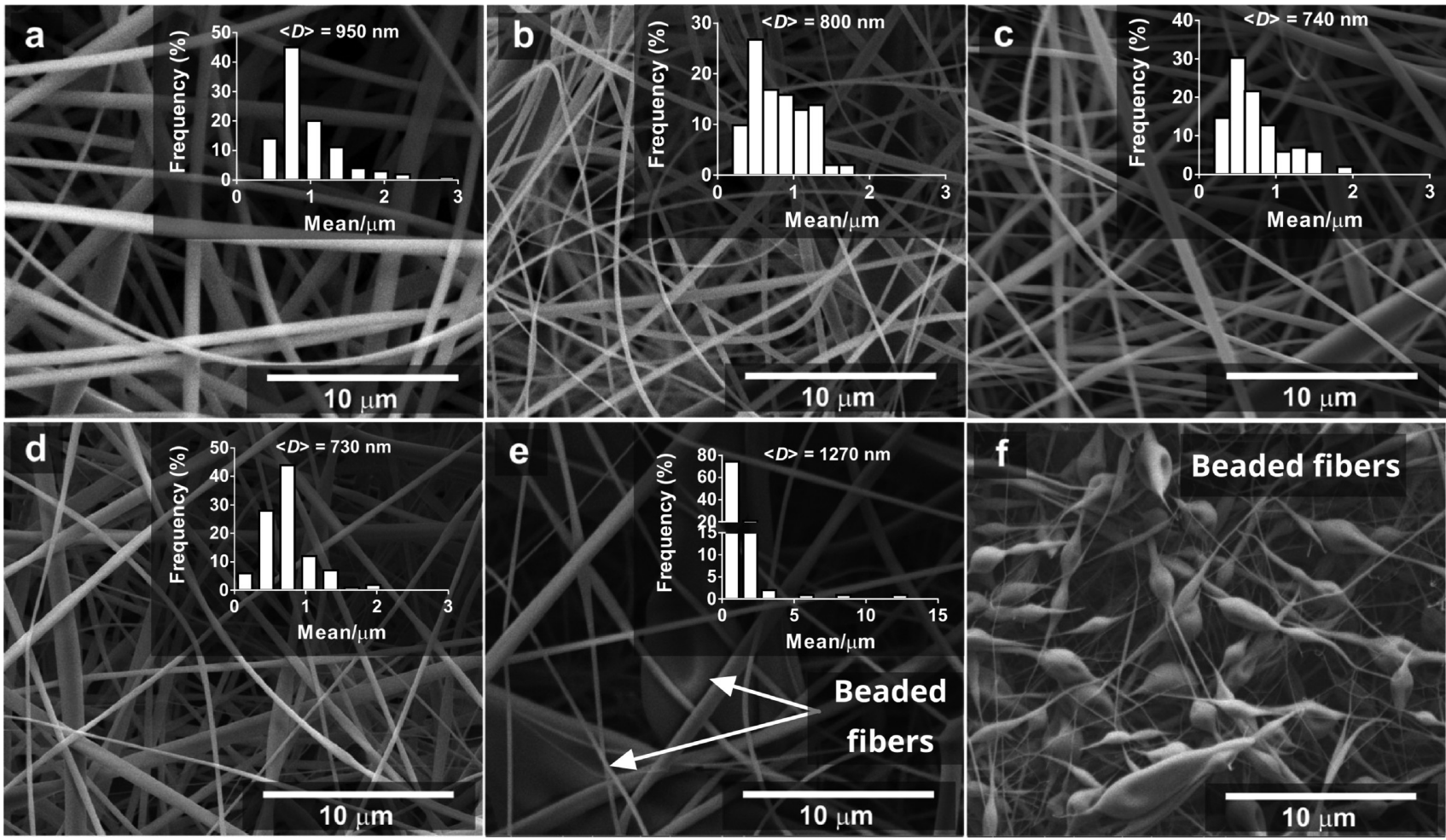

Figure 5. Scanning electron micrographs of the electrospun HP- $\beta$-CD nanofibers $(c=160 \%(\mathrm{w} / \mathrm{v}))$ produced at various urea concentrations: (a) $1 \%(\mathrm{w} / \mathrm{v}),(\mathrm{b}) 2.5 \%(\mathrm{w} / \mathrm{v}),(\mathrm{c}) 5 \%(\mathrm{w} / \mathrm{v}),(\mathrm{d}) 10 \%(\mathrm{w} / \mathrm{v}),(\mathrm{e}) 20 \%(\mathrm{w} / \mathrm{v})$, and (f) $40 \%(\mathrm{w} / \mathrm{v})$. The insets show the size distributions of the nanofibers.
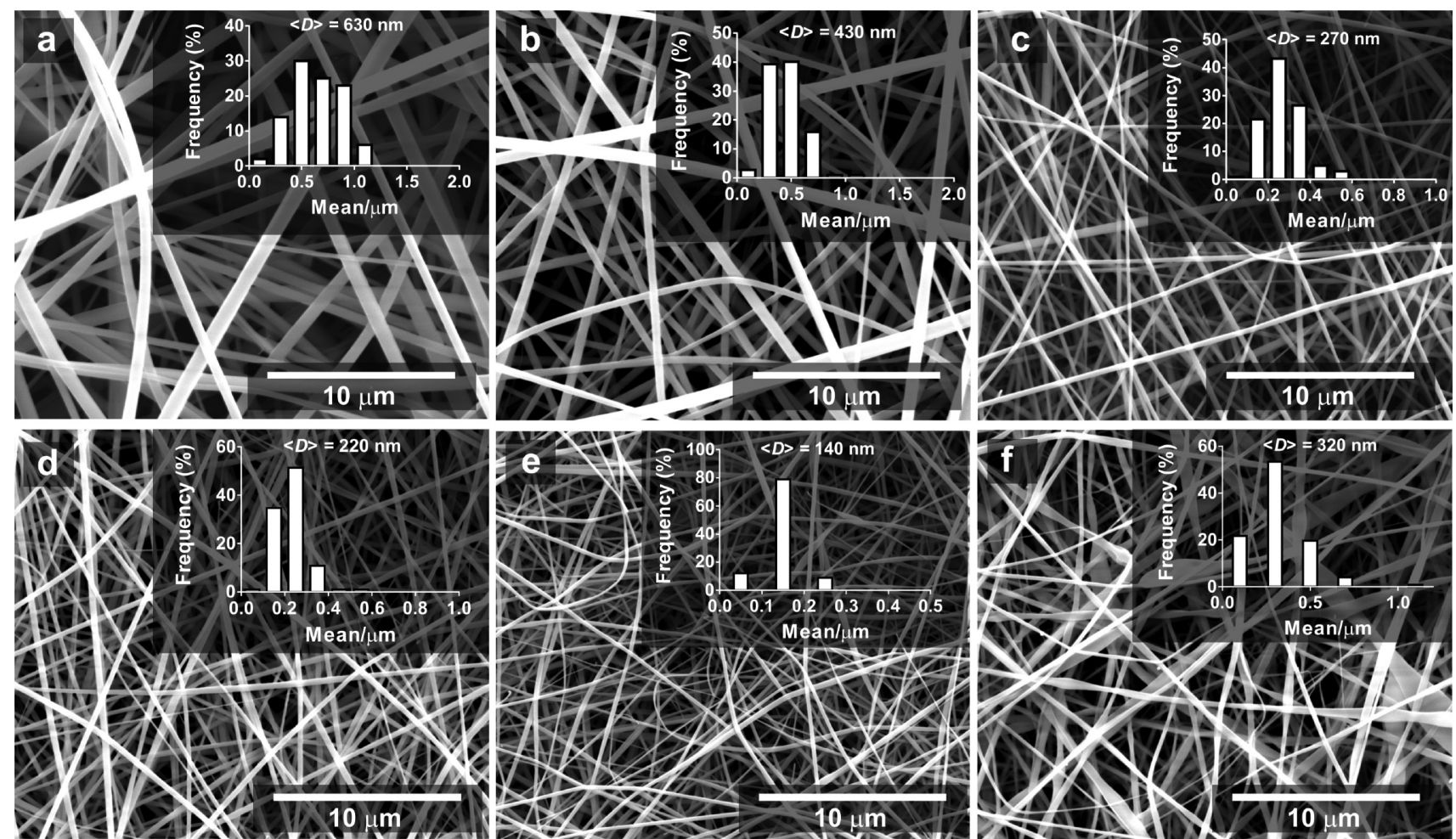

Figure 6. Scanning electron micrographs of the electrospun HP- $\beta$-CD nanofibers $(c=160 \%(\mathrm{w} / \mathrm{v}))$ produced at various ED concentrations: (a) $1 \%(\mathrm{w} / \mathrm{v}),(\mathrm{b}) 2.5 \%(\mathrm{w} / \mathrm{v}),(\mathrm{c}) 5 \%(\mathrm{w} / \mathrm{v}),(\mathrm{d}) 10 \%(\mathrm{w} / \mathrm{v}),(\mathrm{e}) 20 \%(\mathrm{w} / \mathrm{v})$, and $(\mathrm{f}) 40 \%(\mathrm{w} / \mathrm{v})$. The insets show the size distributions of the respective nanofibers.

electrospinning of HP- $\beta$-CD in water $(c=160 \mathrm{wt} \%)$ led to nanofibers in the size range of $250-1780 \mathrm{~nm}$, whereas the electrospinning of HP- $\beta$-CD in DMF at 120 wt \% formed larger nanofibers in the size range of $400-1800 \mathrm{~nm} .{ }^{20}$ When 

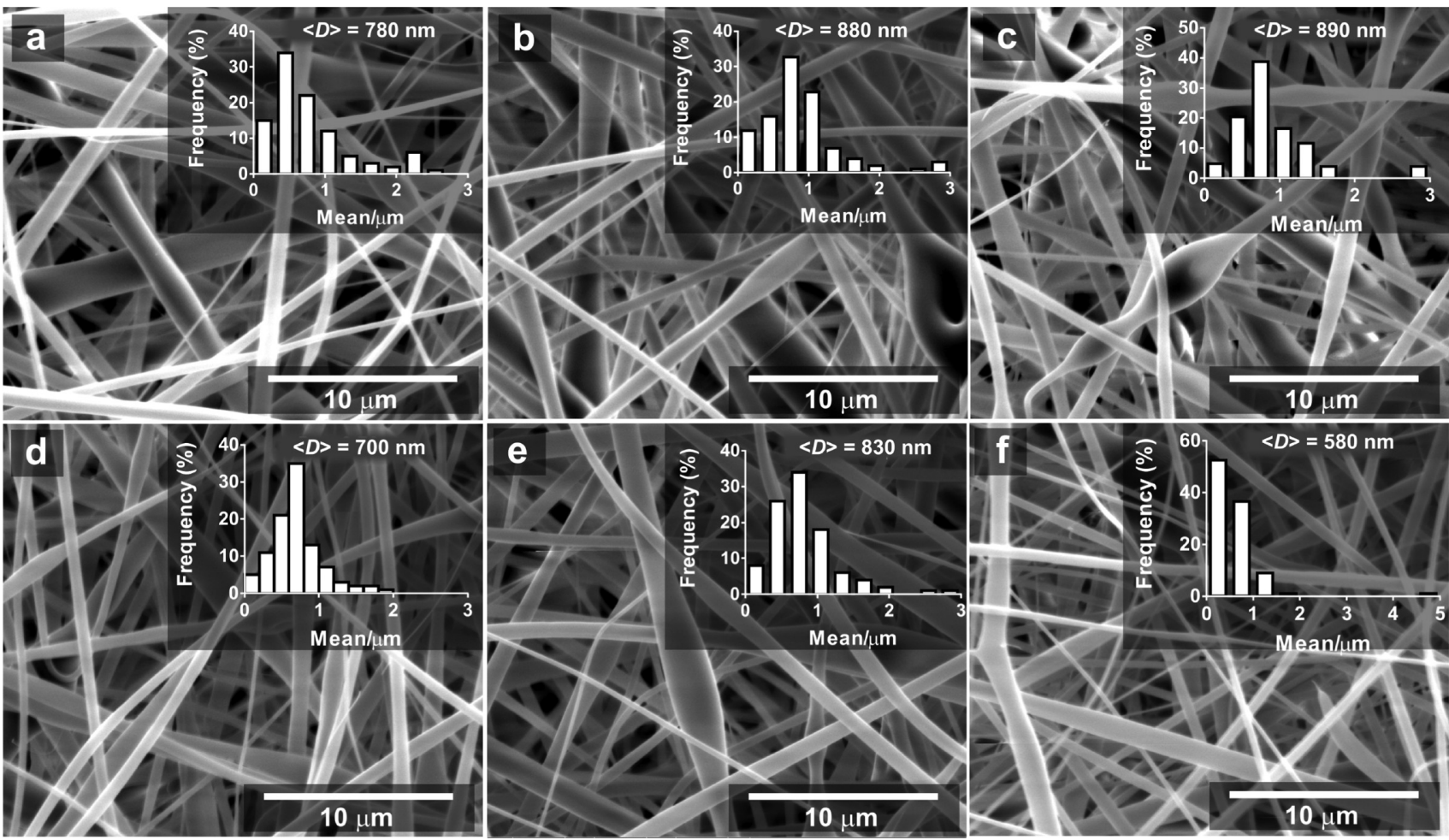

Figure 7. Scanning electron micrographs of the electrospun HP- $\beta$-CD nanofibers $(c=160 \%(\mathrm{w} / \mathrm{v}))$ produced at various HFIP concentrations: (a) $1 \%(\mathrm{w} / \mathrm{v}),(\mathrm{b}) 2.5 \%(\mathrm{w} / \mathrm{v}),(\mathrm{c}) 5 \%(\mathrm{w} / \mathrm{v}),(\mathrm{d}) 10 \%(\mathrm{w} / \mathrm{v}),(\mathrm{e}) 20 \%(\mathrm{w} / \mathrm{v})$, and $(\mathrm{f}) 40 \%(\mathrm{w} / \mathrm{v})$. The insets show the size distributions of the respective nanofibers.

the HP- $\beta$-CD concentration is very low, the occurrence of beaded nanofibers was observed, suggesting that intramolecular interactions between HP- $\beta$-CD aggregates are not strong enough to drive the formation of bead-free nanofibers.

The importance of hydrogen bonding on the electrospinning of HP- $\beta$-CD molecules can also be confirmed by varying the solution $\mathrm{pH}$. The $\mathrm{pH}$ of the electrospinning medium is highly critical for hydrogen-bonded aggregation as in the case of HP$\beta$-CD molecules due to the ionization of $\mathrm{OH}$ groups of $\mathrm{CDs}{ }^{29}$ The viscosities of $160 \%(\mathrm{w} / \mathrm{v}) \mathrm{HP}-\beta$-CD molecules in solutions having $\mathrm{pH}$ values 3 and 14 were measured as 0.331 $( \pm 0.068)$ and $0.525( \pm 0.053) \mathrm{Pa}$ s, respectively, whereas the viscosity of the sample prepared at neutral $\mathrm{pH}$ was 0.677 $( \pm 0.034) \mathrm{Pa}$ s. The nanofibers produced at a $\mathrm{pH}$ of 3 exhibited beaded nanofibers due to lower viscosity of the solution, whereas the nanofibers produced at a $\mathrm{pH}$ of 14 showed beadfree nanofibers, but with decreased electrospinnability (Figure $\mathrm{S} 3$ ). The results suggest that the $\mathrm{pH}$ of the electrospinning solution is important, particularly for those produced from polymer-free hydrogen-bonded assemblies.

The additives with hydrogen-bonding potential can influence the HP- $\beta$-CD aggregation by disturbing hydrogen bonds among HP- $\beta$-CD molecules and hence affect their electrospinning. The urea addition at various concentrations at the constant HP- $\beta$-CD content $(c=160 \%(\mathrm{w} / \mathrm{v}))$ was investigated over the morphology of the resultant nanofibers (Figure 5). The addition of urea caused a significant decrease in the fiber diameter, and above $20 \%(\mathrm{w} / \mathrm{v})$ of urea, beaded nanofibers were observed. A similar observation was also reported by Celebioglu et al. (2012). ${ }^{20}$ The mean size of the nanofibers decreased from 800 to $730 \mathrm{~nm}$ with an increasing urea concentration from 2.5 to $20 \%(\mathrm{w} / \mathrm{v})$. Further, the morphological changes of the nanofibers were supported by the viscosity data of the respective solutions: the viscosity of the HP- $\beta$-CD solutions significantly decreased with a urea concentration rise: the viscosity of the respective solutions decreased from $0.509( \pm 0.038)$ to $0.135( \pm 0.013)$ Pa $s$ with increasing urea concentration from 1 to $40 \%(\mathrm{w} / \mathrm{v})$. The effect of urea on HP- $\beta$-CD electrospinning was also investigated at a lower HP- $\beta$-CD concentration ( $140 \mathrm{wt} \%)$. All fibers revealed beaded structure due to the lower concentration of HP- $\beta$-CD molecules (Figure S4), which could not produce a bead-free fiber structure as revealed with the urea-free sample (Figure $4 \mathrm{e})$. Even at this concentration of HP- $\beta$-CD (i.e., $140 \mathrm{wt} \%$ ), the morphology of beaded fibers transformed into electrosprayed beads at $40 \%(\mathrm{w} / \mathrm{v})$, demonstrating the disruptive effect of urea on the electrospinning of HP- $\beta$-CDs (Figure S5). This is in line with the viscosity of the respective solutions, which drastically decreased from $0.256( \pm 0.035)$ to 0.113 $( \pm 0.026) \mathrm{Pa} s$ with increasing urea concentration from 2.5 to $20 \%(\mathrm{w} / \mathrm{v})$ at the HP- $\beta$-CD concentration of $140 \mathrm{wt} \%$ (Figure S6).

As observed for the addition of urea, the incorporation of ED resulted in the formation of thinner HP- $\beta$-CD nanofibers at low concentrations while beaded nanofibers were observed with a further rise in the concentration of ED to $40 \%(\mathrm{w} / \mathrm{v})$ (Figure 6). The mean fiber diameter decreased from 430 to $320 \mathrm{~nm}$ with increasing ED concentration from 2.5 to $40 \%$ (w/ $v)$. This can also be seen over the viscosity of the respective solutions with an increasing ED concentration. The viscosity of the HP- $\beta$-CD solutions having ED concentration decreased from $0.297( \pm 0.026)$ to $0.235( \pm 0.016)$ Pa $s$ with increasing ED concentration from 1 to $40 \%(\mathrm{w} / \mathrm{v})$. The formation of thinner nanofibers at an increasing ED concentration can be attributed to the disruption of intramolecular interactions between HP- $\beta$-CD molecules, which facilitates their flow. 

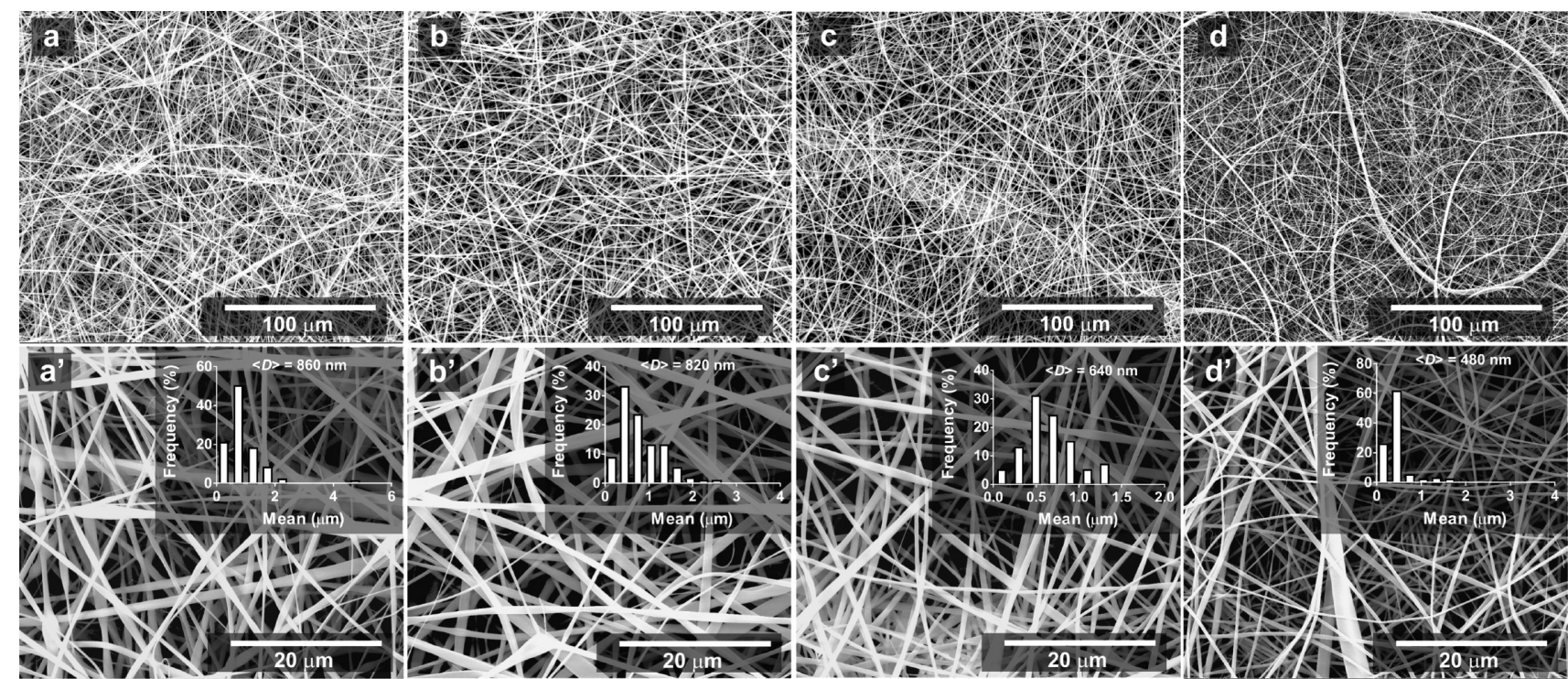

Figure 8. Scanning electron micrographs of the electrospun HP- $\beta$-CD nanofibers $(c=160 \%(\mathrm{w} / \mathrm{v}))$ produced at four different TFE concentrations: $\left(\mathrm{a}, \mathrm{a}^{\prime}\right) 1 \%(\mathrm{w} / \mathrm{v}),\left(\mathrm{b}, \mathrm{b}^{\prime}\right) 5 \%(\mathrm{w} / \mathrm{v}),\left(\mathrm{c}, \mathrm{c}^{\prime}\right) 10 \%(\mathrm{w} / \mathrm{v})$, and $\left(\mathrm{d}, \mathrm{d}^{\prime}\right) 20 \%(\mathrm{w} / \mathrm{v})$. The insets show the size distributions of the respective nanofibers.
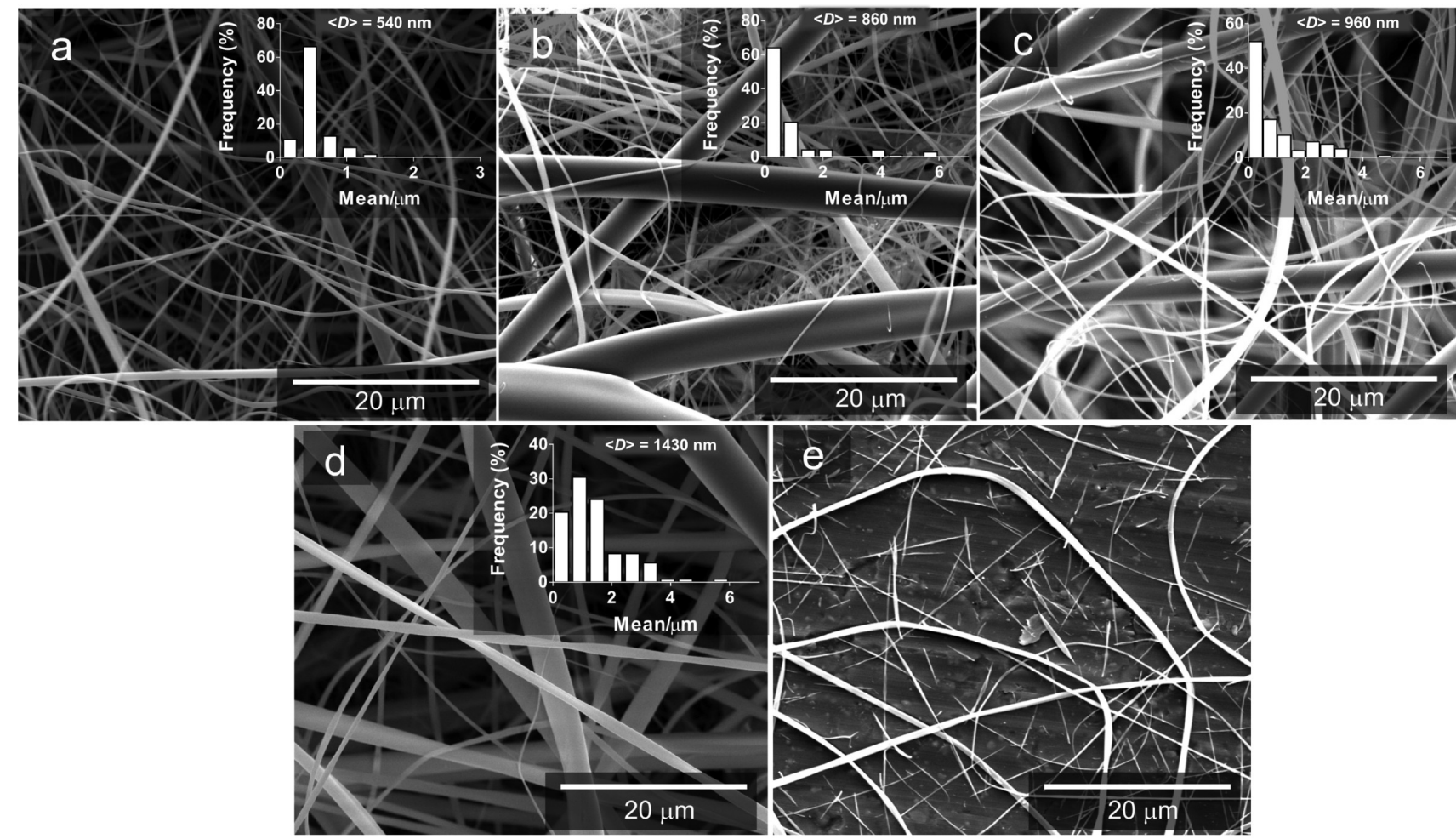

Figure 9. Scanning electron micrographs of the electrospun HP- $\beta$-CD nanofibers $(c=160 \%(\mathrm{w} / \mathrm{v}))$ produced at various MA concentrations: (a) $2.5 \%(\mathrm{w} / \mathrm{v}),(\mathrm{b}) 5 \%(\mathrm{w} / \mathrm{v}),(\mathrm{c}) 10 \%(\mathrm{w} / \mathrm{v}),(\mathrm{d}) 20 \%(\mathrm{w} / \mathrm{v})$, and (e) $40 \%(\mathrm{w} / \mathrm{v})$. The insets show the size distribution plots of the nanofibers.

Further, the appearance of thinner nanofibers in contrast to urea can be associated with the conductivity of the respective solutions. Even though the aqueous solutions of CD containing $\mathrm{ED}$ have higher viscosity than the solutions containing urea, high conductivity may lead to thinner nanofibers by enhancing electrospinnability.

HFIP, i.e., a fluorinated alcohol, is widely used as a polar solvent and known for its strongly hydrogen bond-donating and weakly nucleophilic characters. ${ }^{41}$ It has been used as the solvent for dissolving native $\beta$-CD molecules to a large extent and allowed producing electrospun nanofibers from native $\beta$ -
$\mathrm{CD}$ molecules at low concentrations. In this regard, Akashi and co-workers reported the electrospinning of native $\beta$-CD molecules into well-tuned nanofibers at a very low $\beta$-CD concentration (12.5 wt \%). ${ }^{17}$ In this study, HFIP was used as an additive, and its influence on the HP- $\beta$-CD electrospinning was explored by the morphological analysis of the resultant nanofibers (Figure 7 ). The addition of HFIP into HP- $\beta$-CD solutions led to beaded nanofibers at lower concentration while bead-free HP- $\beta$-CD nanofibers were observed at the HFIP concentration of $40 \%(\mathrm{w} / \mathrm{v})$. The mean fiber diameter 


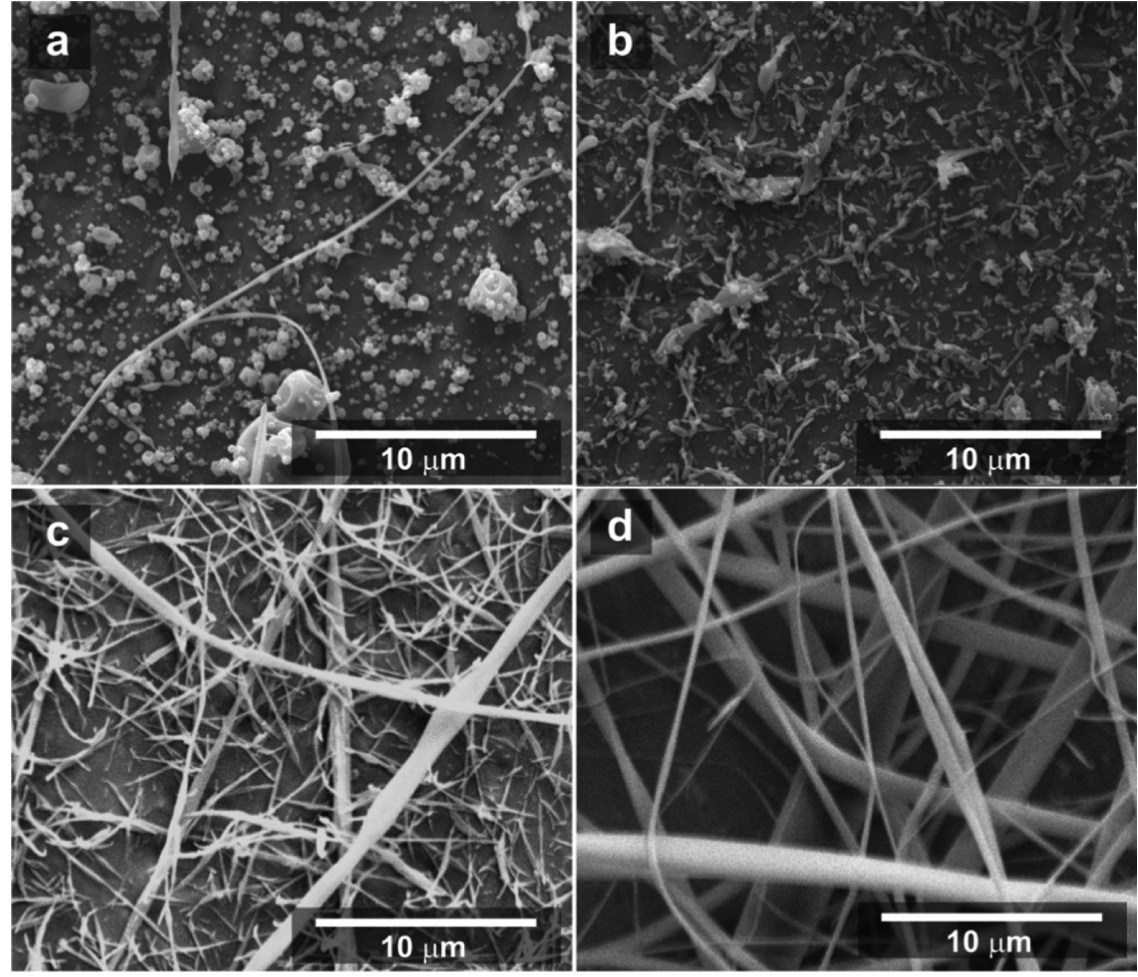

Figure 10. Scanning electron micrographs of the electrospun HP- $\beta$-CD nanofibers produced in the presence of $20 \%$ (w/v) MA. The concentrations of HP- $\beta$-CD are (a) $80 \%(\mathrm{w} / \mathrm{v}),(\mathrm{b}) 100 \%(\mathrm{w} / \mathrm{v}),(\mathrm{c}) 120 \%(\mathrm{w} / \mathrm{v})$, and $(\mathrm{d}) 140 \%(\mathrm{w} / \mathrm{v})$.

decreased from 780 to $580 \mathrm{~nm}$ with increasing HFIP concentration from 1 to $40 \%(\mathrm{w} / \mathrm{v})$.

Another fluoroalcohol, 2,2,2-trifluoroethanol (TFE), was also exploited as an additive into aqueous HP- $\beta$-CD solutions. Like HFIP, TFE also forms hydrogen bonding with HP- $\beta$-CD molecules. The addition of TFE at the concentration of $1 \%$ $(\mathrm{w} / \mathrm{v})$ led to the formation of thinner HP- $\beta$-CD nanofibers (Figure 8), whereas beaded nanofibers were observed at a concentration of $20 \%(\mathrm{w} / \mathrm{v})$. This is consistent with the results of other additives, except MA: first, thinner nanofibers were observed at the low concentration of additives, whereas beaded nanofibers were obtained with increasing concentration. The diameter of the respective nanofibers decreased from 860 to $480 \mathrm{~nm}$ with increasing TFE concentration from 1 to $20 \%(\mathrm{w} /$ v).

The electrospun nanofibers obtained at various MA concentrations showed completely different morphologies from those produced using other additives (Figure 9). Increasing MA concentration led to the formation of larger HP- $\beta$-CD nanofibers until a critical MA concentration, and above this concentration, thinner HP- $\beta$-CD nanofibers were observed: the fiber size increased from 540 to $1430 \mathrm{~nm}$, with an increasing MA concentration from 2.5 to $20 \%(\mathrm{w} / \mathrm{v})$. This is in line with the viscosity data, which revealed a marked rise in the viscosity, followed by a dramatic decrease. The viscosity of the HP- $\beta$-CD solution containing 1 wt \% was measured as $0.477( \pm 0.021) \mathrm{Pa}$ s, while it increased to $516( \pm 68) \mathrm{Pa}$ s with a rise of MA concentration to $20 \mathrm{wt} \%$. The size of electrospun fibers is associated with the solution viscosity, and generally, increasing viscosity led to the formation of larger fibers. In this regard, the higher viscosity of $\mathrm{HP}-\beta-\mathrm{CD} / \mathrm{MA}$ solutions resulted in larger nanofibers. The formation of larger electrospun fibers with MA can be attributed to the enhanced intermolecular associations among $\mathrm{CD}$ molecules. The $\mathrm{pH}$ of the respective solution was measured as 11.98 , which is high enough for the deprotonation of the hydroxyl groups of $\mathrm{CD}$ molecules. On the other hand, the $\mathrm{pH}$ of a HP- $\beta$-CD solution containing $20 \%$ $(\mathrm{w} / \mathrm{v})$ ED was measured as 11.18. Unlike other additives, deprotonated CD molecules in the presence of MA may lead to some physical interactions (i.e., larger fibers). Generally, an increase in the fiber size can be ascribed to the presence of high-degree intra- or intermolecular interactions, which drastically increases apparent molecular weights. ${ }^{42}$

As observed in the viscosity of HP- $\beta$-CD solutions, MA was only the additive that showed an increasing trend in the viscosity with a concentration rise. Therefore, we investigated the influence of MA on the electrospinning of HP- $\beta$-CD solutions with concentrations between 80 and $140 \%(\mathrm{w} / \mathrm{v})$ at the constant MA concentration at $20 \%(\mathrm{w} / \mathrm{v})$ (Figure 10). At 80 and $100 \%(\mathrm{w} / \mathrm{v}) \mathrm{HP}-\beta-\mathrm{CD}$, the electrospraying of HP- $\beta$ $\mathrm{CD}$ solution took place, since the concentration was not high enough to form electrospun nanofibers. At $120 \%(\mathrm{w} / \mathrm{v})$, discontinuous nanofibers were observed while increasing HP$\beta$-CD concentration to $140 \%(\mathrm{w} / \mathrm{v})$ led to the formation of continuous HP- $\beta$-CD nanofibers with a bead-free structure. Thus, the addition of MA assisted in the formation of HP- $\beta$ $\mathrm{CD}$ nanofibers at lower concentration.

The influence of hydrogen-bonding additives on the electrospinning of HP- $\beta$-CD molecules at low concentration (140 wt \%) in the presence of $20 \%(\mathrm{w} / \mathrm{v})$ additive was investigated. All solutions formed homogeneous mixtures (Figure S7) The electrospinning of the solutions, except MA, led to beaded fibers, while uniform bead-free fibers were obtained for MA-containing CD solution (Figure S8). Unlike HFIP, TFE, and urea, the addition of ED tended to form smoother fibers with a bead-on-string structure. Besides their influence on the electrospinning of $\mathrm{CD}$ molecules, the presence of hydrogen-bonding additive significantly affects 
CD-inclusion complexation and decreases the associations with guest molecules as shown with $\mathrm{CD}$-acridine complex by the addition of TFE. ${ }^{43}$

\section{CONCLUSIONS}

The influence of hydrogen bonding additives on the electrospinning of HP- $\beta$-CD molecules was studied. The addition of HFIP, ED, MA, TFE, and urea significantly influenced the flow behavior of the HP- $\beta$-CD solutions. The additives, except MA, decreased the solution viscosity with increasing concentration. On the other hand, MA was the only additive that could increase the viscosity of HP- $\beta$-CD solutions. The occurrence of hydrogen bonding between HP$\beta$-CD and additives was evidenced by ${ }^{1} \mathrm{H}$ NMR analysis with the chemical shift of the HP- $\beta$-CD protons, as well as DLS measurements. As revealed by a viscosity decrease, the additives reduced the fiber size with increasing concentration and led to the formation of beaded nanofibers at high concentrations. Unlike HFIP, ED, TFE, and urea, the addition of MA gave rise to higher viscosity and led to larger nanofibers, while other additives resulted in thinner nanofibers due to a decrease in the solution viscosity. MA was the only additive that could drive the formation of HP- $\beta$-CD nanofibers at low concentrations. The variations in the $\mathrm{pH}$ of the solutions also affected the fiber morphology: the electrospinning of an acidic $\mathrm{HP}-\beta$-CD solution $(\mathrm{pH}=3)$ led to beaded nanofibers owing to the disruption of hydrogen bonds while the electrospinning of an alkaline $\mathrm{HP}-\beta-\mathrm{CD}$ solution $(\mathrm{pH}=14)$ yielded bead-free nanofibers. Overall, this paper shows that the polymer-free electrospinning of $\mathrm{HP}-\beta-\mathrm{CD}$ molecules is highly sensitive against the presence of hydrogen-bonding additives, which severely affect the formation of uniform fiber morphology with respect to their concentrations.

\section{EXPERIMENTAL SECTION}

Materials. Hydroxypropyl- $\beta$-cyclodextrin ( $\mathrm{HP}-\beta$-CD, Cavasol W7 HP, molar substitution per 0.60) was obtained from Wacker Chemie $\mathrm{GmbH}$ (Germany) as a gift sample. Urea (99.8\%, Merck), 2,2,2-trifluoroethanol (TFE (>99\%), SigmaAldrich), methylamine (MA, 40 wt \% solution in $\mathrm{H}_{2} \mathrm{O}$, SigmaAldrich), ethylenediamine (ED (>99.5\%), Sigma-Aldrich), and 1,1,1,3,3,3-hexafluoroisopropanol (HFIP ( $\geq 99 \%)$, Sigma-Aldrich) were purchased and used as received. The electrospinning solutions were prepared using high-purity water from a Millipore Milli-Q system.

Electrospinning of Cyclodextrin Solutions. HP- $\beta-\mathrm{CD}$ was dissolved in water and mixed with an additive molecule, i.e., urea, TFE, MA, HFIP, or ED. The electrospinning was carried out at the HP- $\beta$-CD concentration of 160 wt \% unless otherwise noted, and the concentration of additives was given with respect to water $(\% \mathrm{w} / \mathrm{v})$. The solutions were mixed and then transferred into $1 \mathrm{~mL}$ syringes having blunt-edged metallic needles (Sterican MIX, $18 \mathrm{G} \times 11 / 2^{\prime \prime}$, Braun, Melsungen, Germany). The syringes were placed horizontally on a syringe pump (New Era Pump Systems, NE-300 "Just Infusion" Syringe Pump). The flow rate of CD solutions was set to $0.5 \mathrm{~mL} / \mathrm{h}$ during the electrospinning, and a high-voltage power supply (Matsusada, AU series) was used to apply a constant voltage at $15 \mathrm{kV}$. Randomly oriented nanofibers were deposited on a grounded stationary rectangular metal collector, which was covered by a piece of an aluminum foil at a distance of $15 \mathrm{~cm}$. The electrospinning process was performed at $\sim 24$
${ }^{\circ} \mathrm{C}( \pm 1)$ in an enclosed Plexiglas chamber. For the electrospinning at $\mathrm{pH}$ values 3 and $14, \mathrm{HP}-\beta-\mathrm{CD}$ molecules were dissolved in $0.001 \mathrm{M} \mathrm{HCl}(\mathrm{pH}=3)$ and $1 \mathrm{M} \mathrm{NaOH}(\mathrm{pH}$ $=14$ ) and thereafter electrospun into fibers.

Characterization. Viscosity measurements were performed using an Anton Paar Physica MCR 301 rheometer equipped with a Peltier device for temperature control. The top plate (cone plate $(\mathrm{CP})$, diameter $(D) 50 \mathrm{~mm}, 1^{\circ}$ ) was set at a distance of $104 \mu \mathrm{m}$ prior to the measurements. A solvent trap system was used to minimize water evaporation during rheological testing. Further, the sample perimeter was covered with a low-viscous silicone oil to prevent water evaporation throughout the measurements. Viscosity experiments were performed in the shear rate range of $0.01-2000 \mathrm{~s}^{-1}$, and the viscosity at the shear rate $(\gamma)$ of $0.1 \mathrm{~s}^{-1}$ was taken for comparison. Conductivity measurements were carried out using a conductivity meter (Mettler Toledo) at room temperature. The morphology of the electrospun nanofibers was explored by a Quanta 200 FEG, FEI scanning electron microscope (SEM). Prior to SEM analysis, the fiber samples were sputtered with a thin layer of $\mathrm{Au}(\sim 5 \mathrm{~nm})$, a Gatan 682 Precision Etching and Coating System (PECS). The average diameter and size distribution of the nanofibers were calculated over 100 fibers using SEM images by ImageJ (NIH, Bethesda, $\mathrm{MD})$.

NMR Experiments. ${ }^{1} \mathrm{H}$ NMR spectra of the HP- $\beta-\mathrm{CD}$ molecules in $\mathrm{D}_{2} \mathrm{O}$ were recorded on a Bruker DPX-400 instrument at various concentrations of additives. The spectra were recorded at $400 \mathrm{MHz}$, and a total of 32 scans were taken.

Dynamic Light Scattering (DLS) Experiments. The measurements were performed by a photon correlation spectroscopy using a Malvern Nano ZS ZEN3600 (Malvern Instruments Inc.) at a fixed scattering angle of $173^{\circ}$. HP- $\beta$-CD molecules $(20 \mathrm{mg} / \mathrm{mL})$ dissolved in distilled water and additives with various concentrations were added. Polystyrene cuvettes were used for the measurements, and the data were analyzed by Zetasizer software (Malvern).

\section{ASSOCIATED CONTENT}

\section{Supporting Information}

The Supporting Information is available free of charge on the ACS Publications website at DOI: 10.1021/acsomega.8b02662.

DLS results of aqueous solutions of the HP- $\beta$-CD containing different additives; SEM images of the nanofibers; viscosity plot of the $\mathrm{HP}-\beta-\mathrm{CD}$ solutions; SEM images of the electrospun HP- $\beta$-CD nanofibers produced in the presence of additives (PDF)

\section{AUTHOR INFORMATION}

\section{Corresponding Authors}

*E-mail: fuat.topuz@rwth-aachen.de (F.T.).

*E-mail: tamer@unam.bilkent.edu.tr. Phone: +90 (312) 290 8987 (T.U.).

\section{ORCID}

Fuat Topuz: 0000-0002-9011-4495 Tamer Uyar: 0000-0002-3989-4481

\section{Notes}

The authors declare no competing financial interest. 


\section{REFERENCES}

(1) Crini, G. Review: A History of Cyclodextrins. Chem. Rev. 2014, 114, 10940-10975.

(2) Kata, M.; Selmeczi, B. Increasing the solubility of drugs through cyclodextrin complexation. J. Inclusion Phenom. 1987, 5, 39-43.

(3) Radu, C.-D.; Parteni, O.; Ochiuz, L. Applications of cyclodextrins in medical textiles-review. J. Controlled Release 2016, 224, 146-157.

(4) Buschmann, H. J.; Knittel, D.; Schollmeyer, E. New Textile Applications of Cyclodextrins. J. Inclusion Phenom. Macrocyclic Chem. 2001, 40, 169-172.

(5) Cireli, A.; Birkan, Y. Application of cyclodextrin to the textile dyeing and washing processes. J. Appl. Polym. Sci. 2006, 100, 208218.

(6) Sebaaly, C.; Charcosset, C.; Fourmentin, S.; Greige-Gerges, H. Potential Applications of Cyclodextrin Inclusion Complexes, Liposomes, and Drug-in-Cyclodextrin-in-Liposome in Food Industry and Packaging. In Role of Materials Science in Food Bioengineering; Grumezescu, A. M., Holban, A. M., Eds.; Academic Press, 2018; pp 187-234.

(7) Fenyvesi, É.; Vikmon, M.; Szente, L. Cyclodextrins in Food Technology and Human Nutrition: Benefits and Limitations. Crit. Rev. Food Sci. Nutr. 2016, 56, 1981-2004.

(8) Moya-Ortega, M. D.; Alvarez-Lorenzo, C.; Concheiro, A.; Loftsson, T. Cyclodextrin-based nanogels for pharmaceutical and biomedical applications. Int. J. Pharm. 2012, 428, 152-163.

(9) Loethen, S.; Kim, J. M.; Thompson, D. H. Biomedical Applications of Cyclodextrin Based Polyrotaxanes. Polym. Rev. 2007, 47, 383-418.

(10) Mejia-Ariza, R.; Graña-Suárez, L.; Verboom, W.; Huskens, J. Cyclodextrin-based supramolecular nanoparticles for biomedical applications. J. Mater. Chem. B 2017, 5, 36-52.

(11) Narayanan, G.; Ormond, B. R.; Gupta, B. S.; Tonelli, A. E. Efficient wound odor removal by $\beta$-cyclodextrin functionalized poly ( $\varepsilon$-caprolactone) nanofibers. J. Appl. Polym. Sci. 2015, 132, No. 42782.

(12) Topuz, F.; Uyar, T. Poly-cyclodextrin cryogels with aligned porous structure for removal of polycyclic aromatic hydrocarbons (PAHs) from water. J. Hazard. Mater. 2017, 335, 108-116.

(13) Topuz, F.; Uyar, T. Cyclodextrin-functionalized mesostructured silica nanoparticles for removal of polycyclic aromatic hydrocarbons. J. Colloid Interface Sci. 2017, 497, 233-241.

(14) Alsbaiee, A.; Smith, B. J.; Xiao, L.; Ling, Y.; Helbling, D. E.; Dichtel, W. R. Rapid removal of organic micropollutants from water by a porous $\beta$-cyclodextrin polymer. Nature 2016, 529, 190.

(15) Celebioglu, A.; Yildiz, Z. I.; Uyar, T. Electrospun crosslinked poly-cyclodextrin nanofibers: Highly efficient molecular filtration thru host-guest inclusion complexation. Sci. Rep. 2017, 7, No. 7369.

(16) Celebioglu, A.; Uyar, T. Electrospinning of nanofibers from non-polymeric systems: Electrospun nanofibers from native cyclodextrins. J. Colloid Interface Sci. 2013, 404, 1-7.

(17) Kida, T.; Sato, S.-i.; Yoshida, H.; Teragaki, A.; Akashi, M. 1,1,1,3,3,3-Hexafluoro-2-propanol (HFIP) as a novel and effective solvent to facilely prepare cyclodextrin-assembled materials. Chem. Commun. 2014, 50, 14245-14248.

(18) Ahn, Y.; Kang, Y.; Ku, M.; Yang, Y.-H.; Jung, S.; Kim, H. Preparation of $\beta$-cyclodextrin fiber using electrospinning. RSC Adv. 2013, 3, 14983-14987.

(19) Celebioglu, A.; Uyar, T. Electrospun gamma-cyclodextrin $(\gamma$ $\mathrm{CD})$ nanofibers for the entrapment of volatile organic compounds. RSC Adv. 2013, 3, 22891-22895.

(20) Celebioglu, A.; Uyar, T. Electrospinning of nanofibers from non-polymeric systems: polymer-free nanofibers from cyclodextrin derivatives. Nanoscale 2012, 4, 621-631.

(21) Manasco, J. L.; Saquing, C. D.; Tang, C.; Khan, S. A. Cyclodextrin fibers via polymer-free electrospinning. RSC Adv. 2012, 2, 3778-3784.

(22) Zhang, W.; Chen, M.; Zha, B.; Diao, G. Correlation of polymerlike solution behaviors with electrospun fiber formation of hydroxypropyl- $\beta$-cyclodextrin and the adsorption study on the fiber. Phys. Chem. Chem. Phys. 2012, 14, 9729-9737.

(23) Celebioglu, A.; Uyar, T. Cyclodextrin nanofibers by electrospinning. Chem. Commun. 2010, 46, 6903-6905.

(24) Celebioglu, A.; Uyar, T. Electrospinning of Polymer-free Nanofibers from Cyclodextrin Inclusion Complexes. Langmuir 2011, 27, 6218-6226.

(25) Celebioglu, A.; Kayaci-Senirmak, F.; Ipek, S.; Durgun, E.; Uyar, T. Polymer-free nanofibers from vanillin/cyclodextrin inclusion complexes: high thermal stability, enhanced solubility and antioxidant property. Food Funct. 2016, 7, 3141-3153.

(26) Aytac, Z.; Yildiz, Z. I.; Kayaci-Senirmak, F.; San Keskin, N. O.; Kusku, S. I.; Durgun, E.; Tekinay, T.; Uyar, T. Fast-Dissolving, Prolonged Release, and Antibacterial Cyclodextrin/Limonene-Inclusion Complex Nanofibrous Webs via Polymer-Free Electrospinning. J. Agric. Food Chem. 2016, 64, 7325-7334.

(27) Yildiz, Z. I.; Celebioglu, A.; Uyar, T. Polymer-free electrospun nanofibers from sulfobutyl ether7-beta-cyclodextrin (SBE7- $\beta$-CD) inclusion complex with sulfisoxazole: Fast-dissolving and enhanced water-solubility of sulfisoxazole. Int. J. Pharm. 2017, 531, 550-558.

(28) Allais, M.; Mailley, D.; Hebraud, P.; Ihiawakrim, D.; Ball, V.; Meyer, F.; Hebraud, A.; Schlatter, G. Polymer-free electrospinning of tannic acid and cross-linking in water for hybrid supramolecular nanofibres. Nanoscale 2018, 10, 9164-9173.

(29) Coleman, A. W.; Nicolis, I.; Keller, N.; Dalbiez, J. P. Aggregation of cyclodextrins: An explanation of the abnormal solubility of $\beta$-cyclodextrin. J. Inclusion Phenom. Mol. Recognit. Chem. 1992, 13, 139-143.

(30) Celebioglu, A.; Yildiz, Z. I.; Uyar, T. Thymol/cyclodextrin inclusion complex nanofibrous webs: Enhanced water solubility, high thermal stability and antioxidant property of thymol. Food Res. Int. 2018, 106, 280-290.

(31) Celebioglu, A.; Yildiz, Z. I.; Uyar, T. Fabrication of Electrospun Eugenol/Cyclodextrin Inclusion Complex Nanofibrous Webs for Enhanced Antioxidant Property, Water Solubility, and High Temperature Stability. J. Agric. Food Chem. 2018, 66, 457-466.

(32) Taylor, R. The hydrogen bond between N-H or O-H and organic fluorine: favourable yes, competitive no. Acta Crystallogr., Sect. B: Struct. Sci., Cryst. Eng. Mater. 2017, 73, 474-488.

(33) Rossi, B.; Comez, L.; Fioretto, D.; Lupi, L.; Caponi, S.; Rossi, F. Hydrogen bonding dynamics of cyclodextrin-water solutions by depolarized light scattering. J. Raman Spectrosc. 2011, 42, 1479-1483.

(34) Rosenberg, R. E. Does Fluoromethane Form a Hydrogen Bond with Water? J. Phys. Chem. A 2012, 116, 10842-10849.

(35) Dalvit, C.; Invernizzi, C.; Vulpetti, A. Fluorine as a HydrogenBond Acceptor: Experimental Evidence and Computational Calculations. Chem. - Eur. J. 2014, 20, 11058-11068.

(36) Garnero, C.; Zoppi, A.; Genovese, D.; Longhi, M. Studies on trimethoprim:hydroxypropyl- $\beta$-cyclodextrin: aggregate and complex formation. Carbohydr. Res. 2010, 345, 2550-2556.

(37) Do, T. T.; Van Hooghten, R.; Van den Mooter, G. A study of the aggregation of cyclodextrins: Determination of the critical aggregation concentration, size of aggregates and thermodynamics using isodesmic and $\mathrm{K} 2-\mathrm{K}$ models. Int. J. Pharm. 2017, 521, 318326.

(38) Chay, S. K.; Keating, A. V.; James, C.; Aliev, A. E.; Haider, S.; Craig, D. Q. M. Evaluation of the taste-masking effects of (2hydroxypropyl)- $\beta$-cyclodextrin on ranitidine hydrochloride; a combined biosensor, spectroscopic and molecular modelling assessment. RSC Adv. 2018, 8, 3564-3573.

(39) Elliott, N. B.; Ndou, T.; Warner, I. M. Influence of fluorinated alcohols on cyclodextrin: Pyrene complexation. J. Inclusion Phenom. Mol. Recognit. Chem. 1993, 16, 99-112.

(40) Pirnau, A.; Floare, C. G.; Bogdan, M. The complexation of flurbiprofen with $\beta$-cyclodextrin: a NMR study in aqueous solution. $J$. Inclusion Phenom. Macrocyclic Chem. 2014, 78, 113-120.

(41) Colomer, I.; Batchelor-McAuley, C.; Odell, B.; Donohoe, T. J.; Compton, R. G. Hydrogen Bonding to Hexafluoroisopropanol 
Controls the Oxidative Strength of Hypervalent Iodine Reagents. J. Am. Chem. Soc. 2016, 138, 8855-8861.

(42) McKee, M. G.; Elkins, C. L.; Long, T. E. Influence of selfcomplementary hydrogen bonding on solution rheology/electrospinning relationships. Polymer 2004, 45, 8705-8715.

(43) Schuette, J. M.; Warner, I. M. Interaction of Fluorinated Alcohols with the $\beta$-Cyclodextrin/Acridine Complex. Anal. Lett. 1994, 27, 1175-1182. 